\title{
Results from 8 yrs of susceptibility testing of clinical Mycobacterium tuberculosis isolates in Denmark
}

\author{
V.Ø. Thomsen*, J. Bauer*, T. Lillebaek*, S. Glismann**
}

Results from 8 yrs of susceptibility testing of clinical Mycobacterium tuberculosis isolates in Denmark. V.Ø. Thomsen, J. Bauer, T. Lillebaek, S. Glismann. (C) ERS Journals Ltd 2000. ABSTRACT: Increased rates of multidrug-resistant (MDR) tuberculosis (TB) has been reported from countries close to Denmark. This study evaluated the incidence of drug resistance in Denmark in order to determine the magnitude of the problem.

Susceptibility testing was performed in isolates from $85.4 \%$ of all notified patients during 1991-1998. Epidemiological information was retrieved from the mandatory notification forms.

Total drug resistance remained largely constant, although a minor increase was observed in 1997-1998. Monoresistance was observed in 7.3\%, of the isolates. Among $3.6 \%$ polyresistant isolates, resistance to isoniazid and streptomycin accounted for $2.8 \%$, whereas MDR accounted for $0.5 \%$. The MDR strains displayed different restriction fragment length polymorphism (RFLP) patterns, and no matches were identified in the international MDR database. Drug resistance in untreated Danes and foreigners were $5.9 \%$ and $\mathbf{1 4 . 6 \%}$, respectively. Among Danes and foreigners with previous $\mathrm{TB}, \mathbf{6 . 2 \%}$ and $22.7 \%$ had drug resistance, respectively. Increased drugresistance was found among untreated Danes aged 25-54 yrs mainly due to a single isoniazid and streptomycin-resistant RFLP-cluster. Among all patients with isoniazid and streptomycin-resistance, $77.0 \%$ had clustered strains.

In conclusion, although drug resistance among untreated Danes was close to the rate estimated in good national programmes, close monitoring is needed in future years, as active transmission of isoniazid- and streptomycin-resistant Mycobacterium tuberculosis was demonstrated.

Eur Respir J 2000; 15: 203-208.
*Dept of Mycobacteriology, and **Dept
of Epidemiology, Statens Serum Institut, of Epidemiology, State

Correspondence: V.Ø. Thomsen, Dept of Mycobacteriology, Statens Serum Institut, Artillerivej 5, 2300 Copenhagen S, Denmark. Fax: 4532683871

\section{Keywords: Bactec}

IS6110

multidrug resistance

restriction fragment length polymorphism transmission

tuberculosis

Received: September 161999

Accepted after revision February 72000
Drug-resistant tuberculosis (TB) is caused by inadequate chemotherapy. Several outbreaks of multidrug-resistant (MDR) TB have been reported, e.g. in New York (USA) with the so-called $\mathrm{W}$-strain belonging to the Beijing family [1-3] and in Spain with Mycobacterium bovis [4]. In a recent review covering studies performed during 19851994, CoHn et al. [5] described alarming rates of MDRTB in Nepal (48\%), Guarat in India (34\%), New York in the USA (30\%), Bolivia (15\%) and Korea (15\%) in previously treated patients. The World Health Organization (WHO) has estimated that up to 50 million people may be infected with resistant Mycobacterium tuberculosis globally [6]. MDR-TB treatment is pro longed, has more side effects, and the prospect of cure is lower than for TB caused by sensitive bacteria [7].

The results of drug susceptibility testing are important in two regards: firstly, patients infected with resistant strains achieve a favourable response more often if the treatment is adjusted according to the results of susceptibility testing [8] and secondly, the rate of drug resistance is a useful parameter for monitoring the efficiency of national TB control programmes. The WHO has published guidelines for surveillance of drug-resistant M. tuberculosis [9].

In Denmark, drug susceptibility testing is performed on initial and quarterly isolates of $M$. tuberculosis from new and retreatment TB cases. During 1991-1998 >3,000 iso- lates were tested against critical concentrations of the primary antituberculous drugs at the Dept of Mycobacteriology at Statens Serum Institut (Copenhagen, Denmark), the only laboratory in the country that carries out culture and susceptibility testing of $M$. tuberculosis. The aim of the present study was to analyse nationwide results of susceptibility testing during 1991-1998. The results are analysed with regard to age, nationality, and treatment history. Furthermore, selected data are linked to IS6110 restriction fragment length polymorphism (RFLP) analysis in order to investigate active transmission of resistant strains of $M$. tuberculosis. This study will therefore provide useful parameters for future evaluation of the TB situation in Denmark.

\section{Materials and methods}

\section{Patients}

Patients with culture verified TB during 1991-1998 were identified through the TB registers in the Dept of Mycobacteriology and the Dept of Epidemiology, Statens Serum Institut (Copenhagen, Denmark). The number of notified TB cases, their nationality, and information regarding previous TB was retrieved. Patients born outside of 
Denmark and their children $\leq 25$ yrs of age were regarded as foreigners. All patients with previous TB were regarded retreatment cases although a minority may not have received treatment.

\section{Strains}

If more than one susceptibility test was performed per patient per year, the result of the initial test was used unless MDR M. tuberculosis was cultured from a later specimen. If both pulmonary and extrapulmonary initial isolates were analysed, the result of the pulmonary isolate was chosen. Isolates of $M$. bovis and isolates from patients living in Greenland or on the Faroe Islands were excluded.

\section{Indirect qualitative susceptibility testing}

The isolates were tested with the indirect qualitative method against critical concentrations of rifampicin $(\mathrm{R})$, isoniazid $(\mathrm{H})$, ethambutol $(\mathrm{E})$, and streptomycin $(\mathrm{S})$ in Bactec 12B test medium (Becton-Dickinson, Sparks, MD, USA) and for pyrazinamide $(Z)$ in Bactec PZA test medium (Becton). During the study period, the concentrations were reduced for $\mathrm{H}\left(1.0-0.4 \mathrm{mg} \cdot \mathrm{L}^{-1}\right)$ and $\mathrm{E}\left(7.5-2.5 \mathrm{mg} \cdot \mathrm{L}^{-1}\right)$, whereas the concentrations used for $\mathrm{R}\left(2 \mathrm{mg} \cdot \mathrm{L}^{-1}\right), \mathrm{P}(100$ $\left.\mathrm{mg} \cdot \mathrm{L}^{-1}\right)$, and $\mathrm{S}\left(6.0 \mathrm{mg} \cdot \mathrm{L}^{-1}\right)$ were constant. Isolates were regarded resistant to $\mathrm{R}, \mathrm{H}, \mathrm{E}$ and $\mathrm{S}$ if the daily growth index in the drug-containing vial exceeded that of a $1 \%$ drug-free vial and if attempts to demonstrate the presence of other contaminating micro-organisms including nontuberculous mycobacteria failed (using microscopy and subculture on blood plate from Bactec (Becton-Dickin- son), and careful visual examination of the primary culture media). For $\mathrm{Z}$, the growth in the drug-containing vial was compared to that of a $10 \%$ drug-free vial. Polyresistance was defined as resistance to two or more first line drugs whereas multidrug resistance was defined as resistance to at least $\mathrm{H}$ and $\mathrm{R}$.

\section{Restriction fragment length polymorphism analysis}

IS6110 RFLP has been performed on a routine-basis on isolates from all new TB patients since 1992. The RFLP database comprises results from analysis of initial isolates from $>95 \%$ of all new and retreatment TB cases verified by culture. The analysis was performed using the internationally standardized technique [10]. The results are analysed using the Gelcompar software (Applied Maths, Kortrijk, Belgium) following the published recommendations [11]. The RFLP patterns of the MDR M. tuberculosis isolates were submitted to the international MDR-TB RFLP database in the Dept of Microbiology at the University of Zaragoza, Spain.

\section{Results}

\section{Susceptibility testing}

Susceptibility testing was performed on isolates from $85.4 \%$ of all TB patients notified from 1991 until 1999 (table 1$)$. In 2,745 of $3,081(89.1 \%)$ susceptibility tests, the isolate was fully susceptible to all five drugs investigated. Ten-point-nine per cent of the isolates were resistant to one or more drugs. The proportion of patients with

Table 1. - Results of susceptibility testing of 3,081 strains of Mycobacterium tuberculosis isolated from Danish patients during 1991-1998

\begin{tabular}{|c|c|c|c|c|c|c|c|c|c|c|c|c|c|}
\hline \multirow[t]{2}{*}{ Year } & \multirow{2}{*}{$\begin{array}{c}1991 \\
\mathrm{~T}\end{array}$} & \multirow{2}{*}{$\begin{array}{c}1992 \\
\mathrm{~T}\end{array}$} & \multirow{2}{*}{$\begin{array}{c}1993 \\
\mathrm{~T}\end{array}$} & \multirow{2}{*}{$\begin{array}{c}1994 \\
\mathrm{~T}\end{array}$} & \multicolumn{2}{|c|}{1995} & \multicolumn{2}{|c|}{1996} & \multicolumn{2}{|c|}{1997} & \multicolumn{2}{|c|}{1998} & \multirow[t]{2}{*}{ Total } \\
\hline & & & & & $\mathrm{N}$ & $\mathrm{R}$ & $\mathrm{N}$ & $\mathrm{R}$ & $\mathrm{N}$ & $\mathrm{R}$ & $\mathrm{N}$ & $\mathrm{R}$ & \\
\hline Notified cases & 333 & 355 & 410 & 495 & \multicolumn{2}{|c|}{448} & \multicolumn{2}{|c|}{482} & \multicolumn{2}{|c|}{554} & \multicolumn{2}{|c|}{529} & 3606 \\
\hline Total tested & 269 & 296 & 382 & 412 & 382 & 29 & 383 & 36 & 404 & 44 & 412 & 32 & 3081 \\
\hline Fully susceptible & 242 & 267 & 336 & 375 & 344 & 25 & 350 & 32 & 348 & 40 & 358 & 28 & $2745(89.1)$ \\
\hline Any $\mathrm{H}$ resistance & 14 & 16 & 28 & 13 & 15 & 4 & 16 & 4 & 21 & 1 & 25 & 4 & $161(5.2)$ \\
\hline Any $\mathrm{R}$ resistance & 1 & 0 & 3 & 5 & 2 & 1 & 0 & 2 & 2 & 2 & 2 & 1 & $21(0.7)$ \\
\hline Any E resistance & 1 & 1 & 3 & 4 & 2 & 1 & 0 & 1 & 3 & 1 & 0 & 1 & $18(0.6)$ \\
\hline Any $\mathrm{Z}$ resistance & 6 & 1 & 3 & 3 & 3 & 0 & 2 & 0 & 4 & 0 & 1 & 1 & $24(0.8)$ \\
\hline Any S resistance & 12 & 17 & 34 & 27 & 31 & 2 & 28 & 2 & 45 & 2 & 48 & 3 & $251(8.1)$ \\
\hline $\mathrm{H}$ resistance only & 7 & 10 & 6 & 4 & 3 & 2 & 3 & 1 & 7 & 0 & 7 & 0 & $50(1.6)$ \\
\hline $\mathrm{R}$ resistance only & 0 & 0 & 1 & 1 & 1 & 0 & 0 & 0 & 1 & 1 & 0 & 0 & $5(0.2)$ \\
\hline E resistance only & 1 & 1 & 0 & 0 & 0 & 0 & 0 & 0 & 0 & 0 & 0 & 0 & $2(0.1)$ \\
\hline $\mathrm{Z}$ resistance only & 5 & 1 & 2 & 3 & 1 & 0 & 1 & 0 & 3 & 0 & 0 & 0 & $16(0.5)$ \\
\hline S resistance only & 7 & 11 & 15 & 20 & 20 & 0 & 16 & 0 & 31 & 2 & 29 & 0 & $151(4.9)$ \\
\hline Total monodrug resistance & 20 & 23 & 24 & 28 & 25 & 2 & 20 & 1 & 42 & 3 & 36 & 0 & $224(7.3)$ \\
\hline Total $\mathrm{H}+\mathrm{R}$ resistance (MDR) & 1 & 0 & 2 & 4 & 1 & 1 & 0 & 2 & 1 & 1 & 2 & 1 & $16(0.5)$ \\
\hline $\mathrm{H}+\mathrm{Z}$ resistance & 1 & 0 & 1 & 0 & 0 & 0 & 1 & 0 & 0 & 0 & 0 & 0 & $3(0.1)$ \\
\hline $\mathrm{H}+\mathrm{S}$ resistance & 5 & 6 & 18 & 5 & 10 & 1 & 12 & 1 & 10 & 0 & 15 & 3 & $86(2.8)$ \\
\hline $\mathrm{H}+\mathrm{E}+\mathrm{Z}$ resistance & 0 & 0 & 0 & 0 & 1 & 0 & 0 & 0 & 0 & 0 & 0 & 0 & $1(0.1)$ \\
\hline $\mathrm{H}+\mathrm{E}+\mathrm{S}$ resistance & 0 & 0 & 1 & 0 & 0 & 0 & 0 & 0 & 2 & 0 & 0 & 0 & $3(0.1)$ \\
\hline $\mathrm{H}+\mathrm{E}+\mathrm{Z}+\mathrm{S}$ resistance & 0 & 0 & 0 & 0 & 0 & 0 & 0 & 0 & 1 & 0 & 0 & 0 & $1(0.1)$ \\
\hline $\mathrm{H}+\mathrm{Z}+\mathrm{S}$ resistance & 0 & 0 & 0 & 0 & 0 & 0 & 0 & 0 & 0 & 0 & 1 & 0 & $1(0.1)$ \\
\hline $\mathrm{Z}+\mathrm{S}$ resistance & 0 & 0 & 0 & 0 & 1 & 0 & 0 & 0 & 0 & 0 & 0 & 0 & $1(0.1)$ \\
\hline $\begin{array}{l}\text { Total polyresistance other } \\
\text { than MDR }\end{array}$ & 6 & 6 & 20 & 5 & 12 & 1 & 13 & 1 & 13 & 0 & 16 & 3 & $96(3.1)$ \\
\hline $\begin{array}{l}\text { Proportion of any drug } \\
\text { resistance \% }\end{array}$ & 10.0 & 9.8 & 12.0 & 9.0 & 10. & & 8 & & 13 & & & & 10.9 \\
\hline
\end{tabular}

Values are presented as absolute numbers with percentages in parentheses. One isolate per patient per year is included. T: total; N: new; r: retreatment; H: isoniazid; R: rifampicin; E: ethambutol; Z: pyrazinamide; S: streptomycin; MDR: multidrug resistance. 
Table 2. - Proportion of drug resistance in untreated patients

\begin{tabular}{|c|c|c|c|c|c|c|c|c|c|c|}
\hline & \multicolumn{2}{|c|}{1995} & \multicolumn{2}{|c|}{1996} & \multicolumn{2}{|c|}{1997} & \multicolumn{2}{|c|}{1998} & \multicolumn{2}{|c|}{ Total } \\
\hline & $\mathrm{D}$ & $\mathrm{F}$ & $\mathrm{D}$ & $\mathrm{F}$ & D & $\mathrm{F}$ & $\mathrm{D}$ & $\mathrm{F}$ & $\mathrm{D}$ & $\mathrm{F}$ \\
\hline No. of patients & 158 & 224 & 151 & 232 & 122 & 282 & 146 & 266 & 577 & 1004 \\
\hline No. of patients with resistant isolates & 13 & 25 & 8 & 25 & 4 & 52 & 9 & 45 & 34 & 147 \\
\hline Proportion of drug resistance in untreated patients \% & 8.2 & 11.2 & 5.3 & 10.8 & 3.3 & 18.4 & 6.2 & 16.9 & 5.9 & 14.6 \\
\hline
\end{tabular}

D: Danes; F: foreigners.

resistant isolates of $M$. tuberculosis remained largely constant during the period, although minor increases to $13.4 \%$ and $13.1 \%$ were observed in 1997 and 1998, respectively. Monoresistance was observed in $7.3 \%$ of the isolates, most commonly against either $\mathrm{H}(1.6 \%)$ or against $\mathrm{S}(4.9 \%)$, whereas monoresistance against $\mathrm{R}$, E, and $\mathrm{Z}$ was uncommon. Polyresistance was observed in 3.6\% of the isolates. Among these, resistance to $\mathrm{H}$ and $\mathrm{S}$ accounted for $2.8 \%$ whereas MDR accounted for $0.5 \%$. Other infrequently observed combinations of drug resistance included $\mathrm{H}+\mathrm{Z}, \mathrm{H}+\mathrm{E}+\mathrm{Z}, \mathrm{H}+\mathrm{E}+\mathrm{S}, \mathrm{H}+\mathrm{E}+\mathrm{Z}+\mathrm{S}, \mathrm{H}+$ $\mathrm{Z}+\mathrm{S}$, and $\mathrm{Z}+\mathrm{S}$. No other combinations were observed.

Drug resistance among untreated versus previously treated tuberculosis patients

Analysis of drug resistance among untreated Danes and foreigners and previously treated is presented in tables 2 and 3, respectively. Drug resistance in untreated Danes was $5.9 \%$ as compared to $14.6 \%$ in foreigners. Among patients with previous TB, drug resistance was detected in $6.2 \%$ and $22.7 \%$ of all Danes and foreigners, respectively. Drug resistance among different age groups in untreated Danes is presented in table 4. Patients aged 25-54 yrs had significantly higher rates of drug resistance (Chi-squar$\mathrm{ed}=9.3, \mathrm{p}=0.002$ ) than other age groups. Of 29 untreated Danes aged 25-54 yrs with resistant TB diagnosed during 1995-1998, 13 (44.8\%) had TB due to infection with $\mathrm{H}$ and $\mathrm{S}$ resistant $M$. tuberculosis.

Restriction fragment length polymorphism analysis of isoniazid and streptomycin resistant strains

Among all 81 patients identified during 1992-1998 with H- and S-resistant TB, $74(91.4 \%)$ had their isolates analysed by RFLP. Of these, 17 (23.0\%) had strains with unique RFLP patterns whereas $57(77.0 \%)$ had strains that belonged to known RFLP clusters, i.e. strains with identical RFLP patterns except in one case where a one band difference was accepted. Forty (54.1\%) patients had isolates that belonged to one of three different clusters (C), C82, C-3, and C-27 (fig. 1). The majority of these patients
(36 of 40) suffered from pulmonary TB with 24 cases being smear positive.

C-82 comprised 11 patients: nine from Somalia and two from Denmark (10 $\mathrm{H}+\mathrm{S}$ resistant, one $\mathrm{H}$ resistant). It was found in a city in the Western part of Denmark. Since 1997, no new cases have been identified belonging to this cluster.

During the study period, C-27 comprised eight patients: seven from Somalia and one from Lebanon (five $\mathrm{H}+\mathrm{S}$ resistant, three fully sensitive). During the first 8 months of 1999 a further six children and young adults belonging to this cluster were identified (one fully sensitive, five $\mathrm{H}+\mathrm{S}$ resistant). The patients with sensitive isolates were living in different geographic areas, while the patients with drug resistance were living in Copenhagen (Denmark). An epidemiological linkage has been proven for some of the drug resistant patients in C-27: two patients are brothers; and one adult infected four children of a family with whom the patient lived shortly and a child from Lebanon that lived in the same premises as this family (personal communication).

C-3 comprised 28 patients: 19 originating from Scandinavia; one from Somalia; and eight from Greenland and is found in Copenhagen (Denmark; $25 \mathrm{H}+\mathrm{S}$ resistant, three resistant to either $\mathrm{H}$ or $\mathrm{S}$ ). An epidemiological linkage between patients in C-3 has been established [12]. The transmission is associated with a part of Copenhagen characterized by people with poor health and low social status. Among 13 untreated Danes aged 25-54 yrs with $\mathrm{H}$ - and S-resistant TB, $11(84.6 \%)$ had isolates belonging to $\mathrm{C}-3$ and one patient had an isolate that belonged to $\mathrm{C}-82$.

\section{Multidrug-resistant Mycobacterium tuberculosis}

MDR M. tuberculosis was isolated from 15 patients of whom one had two specimens included in the survey. Demographic and microbiological data on these patients are presented in table 5. One patient of foreign origin was coinfected with human immunodeficiency virus (HIV). Twelve patients had pulmonary TB, of whom nine were smear positive. Thirteen patients had their MDR-strain analysed by IS6110 RFLP (fig. 2). None of these strains exhibited identical patterns, but two strains were closely

Table 3. - Proportion of drug resistance in previously treated patients

\begin{tabular}{|c|c|c|c|c|c|c|c|c|c|c|}
\hline & \multicolumn{2}{|c|}{1995} & \multicolumn{2}{|c|}{1996} & \multicolumn{2}{|c|}{1997} & \multicolumn{2}{|c|}{1998} & \multicolumn{2}{|c|}{ Total } \\
\hline & $\mathrm{D}$ & $\mathrm{F}$ & $\mathrm{D}$ & $\mathrm{F}$ & $\mathrm{D}$ & $\mathrm{F}$ & $\mathrm{D}$ & F & $\mathrm{D}$ & $\mathrm{F}$ \\
\hline No. of patients & 17 & 12 & 26 & 10 & 30 & 14 & 24 & 8 & 97 & 44 \\
\hline No. of patients with resistant isolates & 2 & 2 & 1 & 3 & 1 & 3 & 2 & 2 & 6 & 10 \\
\hline Proportion of drug resistance in previously treated patients $\%$ & 11.8 & 16.7 & 3.8 & 30.0 & 3.3 & 21.4 & 8.3 & 25.0 & 6.2 & 22.7 \\
\hline
\end{tabular}

D: Danes; F: foreigners. 
Table 4. - Proportion of resistant cases among untreated Danes

\begin{tabular}{|c|c|c|c|c|c|c|c|}
\hline \multirow{2}{*}{$\begin{array}{l}\text { Age } \\
\text { yrs }\end{array}$} & \multicolumn{4}{|c|}{ Resistant cases } & \multirow{2}{*}{$\begin{array}{l}\text { Total number of } \\
\text { resistant cases }\end{array}$} & \multirow{2}{*}{$\begin{array}{l}\text { Total number } \\
\text { of cases }\end{array}$} & \multirow{2}{*}{$\begin{array}{c}\text { Proportion of resistant } \\
\text { cases } \%\end{array}$} \\
\hline & 1995 & 1996 & 1997 & 1998 & & & \\
\hline $0-14$ & 0 & 0 & 0 & 0 & 0 & 18 & 0.0 \\
\hline $15-24$ & 0 & 0 & 0 & 0 & 0 & 24 & 0.0 \\
\hline $25-34$ & 3 & 1 & 0 & 3 & 7 & 78 & 9.0 \\
\hline $35-44$ & 6 & 1 & 1 & 3 & 11 & 142 & 7.7 \\
\hline $45-54$ & 2 & 5 & 2 & 2 & 11 & 129 & 8.5 \\
\hline $55-64$ & 1 & 0 & 0 & 1 & 2 & 64 & 3.1 \\
\hline $65+$ & 1 & 1 & 1 & 0 & 3 & 122 & 2.5 \\
\hline Total & 13 & 8 & 4 & 9 & 34 & 577 & 5.9 \\
\hline
\end{tabular}

related to the $\mathrm{W}$-strains described previously [3]. These two strains were isolated from the Danish patient assumed to have been infected in Nepal and from a child from the Philippines. Of the remaining 11 RFLP analysed MDR strains, six were unique and five belonged to different clusters that comprised two to 16 patients. The other patients belonging to these five clusters had susceptible isolates and originated from the same country as the patient with MDR-TB. The MDR strains have been submitted to the international MDR RFLP database where no identical matches were found.

\section{Discussion}

This study shows that drug-resistant TB is still a minor problem in Denmark, although a minor increase was observed in 1997-1998. The Danes have unique opportunities for surveillance of TB since notification has been mandatory since 1905 and all data are collected at Statens Serum Institut at the Depts of Epidemiology and Mycobacteriology (Copenhagen, Denmark). The Dept of Mycobacteriology is the only laboratory in Denmark that carries out culture, susceptibility testing and subtyping of mycobacteria although regional laboratories may perform smear microscopy for acid fast bacilli.

In Denmark, treatment of TB normally consists of 3 months of daily R, H, Z, and E followed by 3 months of R and $\mathrm{H}$. For patients suffering from MDR TB, treatment is based on susceptibility testing and information regarding prior treatment, and is centralized to Copenhagen University Hospital (Denmark), which has expertise in the use of second line anti-tuberculous drugs.

Drug-resistant $M$. tuberculosis was isolated from just over $10 \%$ of the TB patients during 1991-1998 although a minor increase was observed in 1997 and 1998. Monodrug resistance was mainly due to $\mathrm{S}$ or $\mathrm{H}$ that were introduced in the late 1940s and early 1950 s as the first antituberculous drugs in Denmark. Resistance to $\mathrm{R}, \mathrm{E}$, and $\mathrm{Z}$ was found rarely in this study and $\mathrm{R}$ resistance is therefore still a good marker for MDR M. tuberculosis in Denmark. Polyresistance was observed in isolates from $3.6 \%$ of all patients and was mainly due to $\mathrm{H}$ and $\mathrm{S}$.

The proportion of drug resistance in patients previously treated was $6.2 \%$ in Danes and $22.7 \%$ in patients from abroad. These proportions reflect the access to resources, and from this the quality of treatment in prior years in the respective countries. However, these figures may represent a minor underestimation as the authors regarded all patients with prior TB as treated patients. A minority may not have received anti-tuberculous chemotherapy as they suffered from TB before the era of chemotherapy or because chemotherapy was not available.

The proportion of drug resistance among untreated patients reflects the transmission of drug resistant bacteria in the society. In Danish patients, the proportion was close to $\leq 5 \%$ as reported by the WHO [13] as being the level in good national programmes. The proportion of drug resistance in untreated foreigners was $14.6 \%$. The difference between Danes and foreigners probably reflects the fact that the patients contracted their infection in geographic areas with different levels of resistance. Although TB patients of foreign origin infected with resistant $M$. tuberculosis could pose a risk to the Danish population, RFLP analysis has revealed that transmission between Danes and foreigners rarely takes place [14].

The limited number of children and adolescent Danish TB patients makes it difficult to estimate whether active transmission of drug-resistant $M$. tuberculosis is ongoing. By application of RFLP analysis, however, it has been shown that the majority of drug resistant TB cases among untreated Danes aged 25-54 yrs were most likely due to recent transmission with $\mathrm{H}$ - and S-resistant $M$. tuberculosis. Treatment compliance and response must be evaluated even more thoroughly in these patients in order to prevent the development of further resistance, especially towards R. The observation of likely transmission with

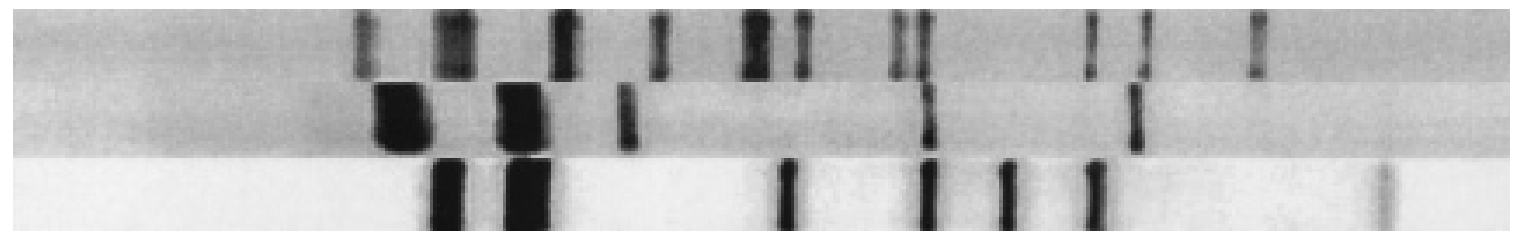

Fig. 1. - Restriction fragment length polymorphism patterns representing three clusters (C) with isoniazid and streptomycin resistant strains. 
Table 5. - Demographic and microbiological data on 15 patients with multidrug-resistant (MDR) Mycobacterium tuberculosis isolated in Denmark during 1991-1998

\begin{tabular}{|c|c|c|c|c|c|c|c|}
\hline $\begin{array}{l}\text { MDR } \\
\text { case No. }\end{array}$ & Year & $\begin{array}{l}\text { Age } \\
\text { yrs }\end{array}$ & Sex & $\begin{array}{l}\text { First TB episode } \\
\text { year/country }\end{array}$ & $\begin{array}{l}\text { Country of } \\
\text { origin }\end{array}$ & Localization & $\begin{array}{l}\text { Sputum } \\
\text { smear }\end{array}$ \\
\hline 1 & 1991 & 31 & M & 1991/Denmark & Peru & Pulmonary & Negative \\
\hline 2 & 1993 & 45 & M & 1993/Denmark & Former Yugoslavia & Pulmonary & Positive \\
\hline 3 & 1993 & 36 & $\mathrm{~F}$ & 1992/Denmark & Denmark & Pulmonary & Positive \\
\hline 4 & 1994 & 34 & $\mathrm{~F}$ & 1994/Denmark & Philippines & Lymph node & - \\
\hline 5 & 1994 & 64 & M & 1986/Somalia & Somalia & Pulmonary & Positive \\
\hline 6 & 1994 & 46 & M & Unknown/Turkey & Turkey & Pulmonary & Positive \\
\hline 7 & 1994 & 7 & M & 1993/Somalia & Somalia & Lymph node & - \\
\hline 8 & 1995 & 35 & $\mathrm{~F}$ & 1994/Philippines & Philippines & Pulmonary & Positive \\
\hline 9 & 1995 & 64 & M & Unknown/Vietnam & Vietnam & Pulmonary & Positive \\
\hline 10 & 1996 & 29 & M & 1994/Denmark & Iraq & Pulmonary & Positive \\
\hline 11 & 1996 & 3 & M & 1995/Philippines & Philippines & Pulmonary & Negative \\
\hline 12 & 1997 & 18 & $\mathrm{~F}$ & 1997/Denmark & Somalia & Pulmonary + genitourinary & Negative \\
\hline 13 & 1998 & 33 & $\mathrm{~F}$ & 1993/Vietnam & Vietnam & Pulmonary & Positive \\
\hline 14 & 1998 & 31 & $\mathrm{~F}$ & 1998/Denmark & Uganda & Pulmonary & Positive \\
\hline 15 & 1998 & 29 & M & 1998/Denmark & Pakistan & Lymph node & - \\
\hline
\end{tabular}

TB: tuberculosis; M: male; F: female.

drug-resistant $M$. tuberculosis among untreated Danes aged 25-54 yrs may have important implications for the clinical management of TB. In the older Danes, only a low proportion were infected with drug-resistant strains either because they were infected years ago when drug resistance was less prevalent, or because they were infected in a part of the Danish society where drug resistance was uncommon.
In this 8-yr survey the authors have observed very few cases of MDR TB. Although the majority of MDR-TB patients had smear positive pulmonary specimens, no secondary cases of MDR-TB in Denmark have been observed. The RFLP patterns of the Danish MDR strains were also different from RFLP patterns of MDR strains submitted to the international MDR database from other countries. Fourteen patients of foreign origin and one

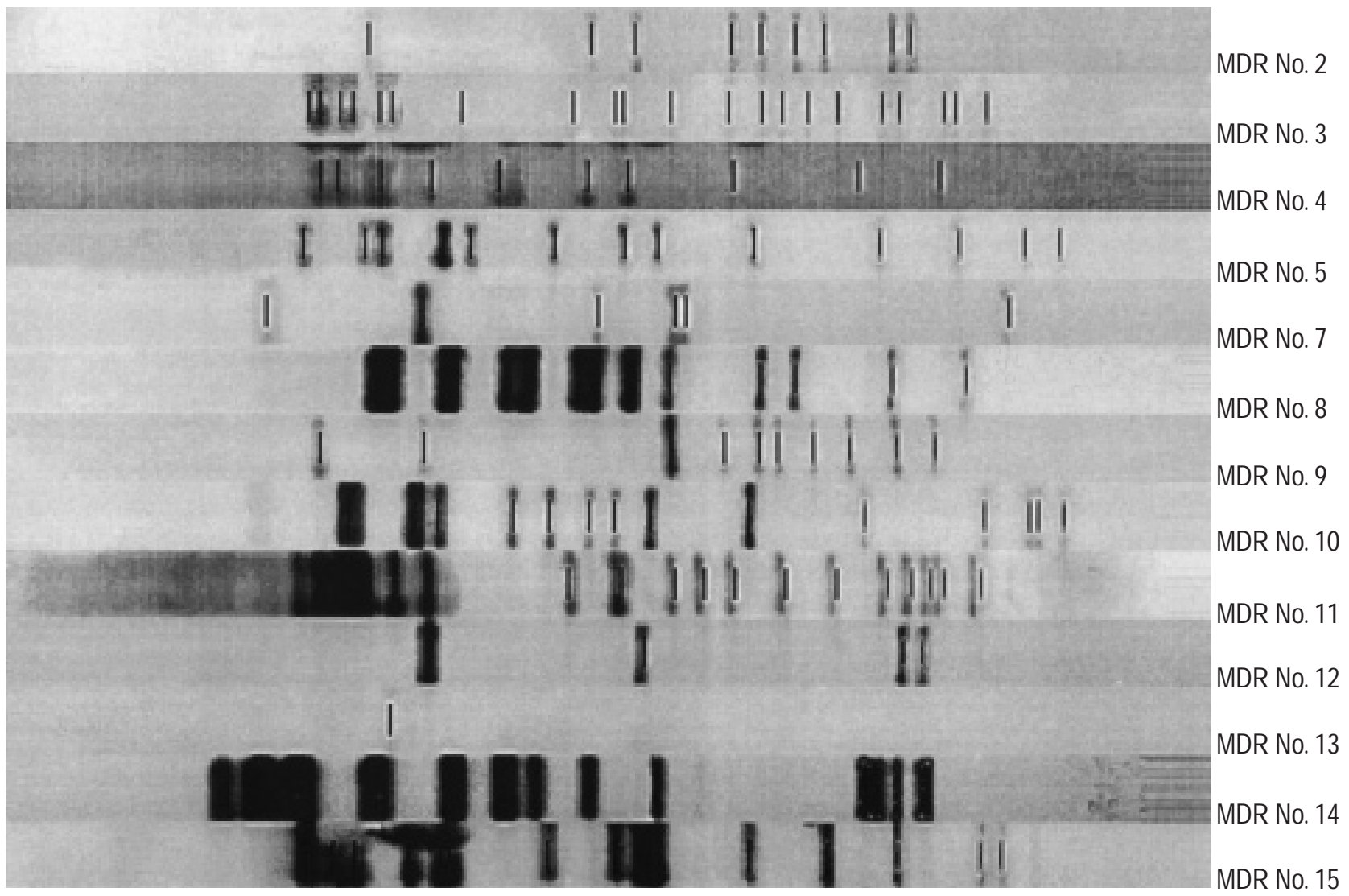

Fig. 2. - Restriction fragment length polymorphism (RFLP) patterns representing 13 of 15 multidrug-resistant (MDR) tuberculosis patients identified in Denmark during 1991-1998. All isolates of MDR Mycobacterium tuberculosis had different RFLP patterns. MDR numbers relate to table 5. 
Danish patient were assumed infected abroad. One patient of foreign origin originally had susceptible TB, but developed MDR-TB because of poor compliance with the treatment in Denmark.

The observation in 1998 of MDR TB in an HIV-positive patient, was the first of its kind in Denmark. The patient was of foreign origin and probably infected abroad with HIV as well as with MDR M. tuberculosis. Of the other 14 cases of MDR M. tuberculosis, 13 were confirmed having negative HIV serology and one was of unknown status at the time of the MDR TB diagnosis. The introduction of MDR-TB into the HIV-wards is a major concern, as transmission in this setting could have fatal consequences.

Although drug resistance among untreated Danes was close to the rate estimated in good national programmes (by the World Health Organization), close monitoring is needed in future years, as active transmission of isoniazidand streptomycin-resistant Mycobacterium tuberculosis was demonstrated.

\begin{abstract}
Acknowledgements. The authors gratefully acknowledge the outstanding work of the technicians Y. Pedersen, G. Danielsen, T. Andresen and K.Ø. Lund who have carried out all the susceptibility tests during this 8-yr period. Thanks to physicians and nurses from all over Denmark for providing clinical data and specimens for examination.
\end{abstract}

\section{References}

1. Centers for Disease Control and Prevention. Nosocomial transmission of multidrug-resistant tuberculosis among HIV-infected persons-Florida and New York, 1988-1991. Morbid Mortal Weekly Rep 1991; 40: 585-591.

2. Centers for Disease Control and Prevention. Transmission of multidrug-resistant tuberculosis among immunocompromised persons in a correctional system-New York, 1991. Morbid Mortal Weekly Rep 1992; 41: 507-509.

3. Coronado VG, Beck Sague CM, Hutton MD, et al. Transmission of multidrug-resistant Mycobacterium tuberculosis among persons with human immunodeficiency virus infection in an urban hospital: epidemiologic and restriction fragment length polymorphism analysis. $J$ Infect Dis 1993; 168: 1052-1055.

4. Samper S, Martin C, Pinedo A, et al. Transmission between HIV-infected patients of multidrug-resistant tuberculosis caused by Mycobacterium bovis. AIDS 1997; 11: 1237-1242.

5. Cohn DL, Bustreo F, Raviglione MC. Drug-resistant tuberculosis: review of the worldwide situation and the WHO/IUATLD Global Surveillance Project. International Union Against Tuberculosis and Lung Disease. Clin Infect Dis 1997; 24 (Suppl. 1): S121-S130.

6. WHO, Geneva. Tuberculosis Fact Sheet. 1998 WHO tuberculosis site http://www.who.int/gtb/publications/factsheet/index.thm.

7. Manalo F, Tan F, Sbarbaro JA, Iseman MD. Communitybased shortcourse treatment of pulmonary tuberculosis in a developing nation. Am Rev Respir Dis 1990; 142: 13011305.

8. Hong Kong Tuberculosis Treatment Services-British Medical Research Council Investigation. A study in Hong Kong to evaluate the role of pretreatment susceptibility tests in the selection of regiments of chemotherapy for pulmonary tuberculosis. Am Rev Respir Dis 1972; 106: 122.

9. WHO Geneva/IUATLD Paris. Guidelines for surveillance of drug resistance in tuberculosis. Int J Tuberc Lung Dis 1998; 2: 72-89.

10. van Embden JD, Cave MD, Crawford JT, et al. Strain identification of Mycobacterium tuberculosis by DNA fingerprinting: recommendations for a standardized methodology. J Clin Microbiol 1993; 31: 406-409.

11. Heersma H, Kremer K, van Embden JDA. Computer analysis of IS6110 RFLP patterns of Mycobacterium tuberculosis. Methods Mol Biol 1998; 101: 395-422.

12. Bauer J. Molecular epidemiology studies of the Mycobacterium tuberculosis complex and the Mycobacterium avium complex. Appendix 6. $\mathrm{PhD}$ thesis, Dept of Mycobacteriology, Statens Serum Institut, Copenhagen Denmark, 1999.

13. Crofton J, Chaulet P, Maher D. Guidelines for the management of drug-resistant tuberculosis. World Health Organization, Geneva, Switzerland, 1997; p. 10.

14. Bauer J, Yang Z, Poulsen S, Andersen AB. Results from 5 years of nationwide DNA fingerprinting of Mycobacterium tuberculosis complex isolates in a country with a low incidence of M. tuberculosis infection. J Clin Microbiol 1998; 36: 305-308. 